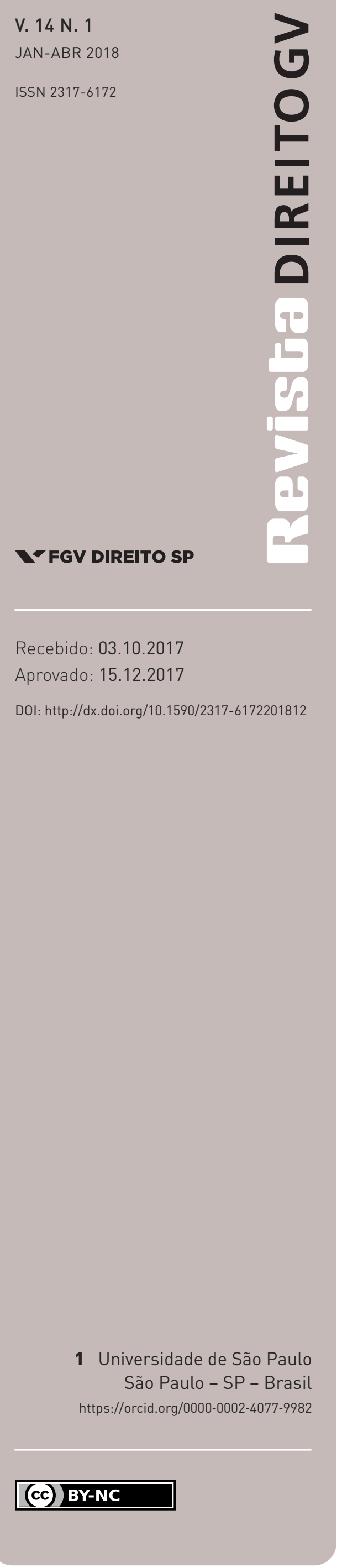

\title{
O direito como revelador das transformações sociais contemporâneas: a abordagem sociopolítica de Jacques Commaille
}

LAW AS A REVELATOR OF CONTEMPORARY SOCIAL TRANSFORMATIONS: THE SOCIOPOLITICAL APPROACH OF JACQUES COMMAILLE

Orlando Villas Bôas Filho'

Resenha do livro: COMMAILLE, JACQUES. À QUOI NOUS SERT LE DROIT? PARIS: GallimARD, 2015. 522 P. 
A obra de Jacques Commaille constitui, seguramente, uma das mais importantes expressões da sociologia jurídica francófona contemporânea. Tendo realizado sua formação junto a grandes figuras do cenário intelectual francês, tais como Georges Gurvitch, Raymond Aron e Pierre Bourdieu, o autor iniciou suas análises acerca do direito vinculado ao jurista Jean Carbonnier, a quem auxiliou, na qualidade de sociólogo, por ocasião da reforma do Código Civil, em meados da década de 1970. A partir dessa experiência, em que tomou contato com as técnicas de produção legislativa e com as dinâmicas políticas envolvidas nessa atividade, Commaille desenvolveu uma "sociologia política do direito" que, segundo André-Jean Arnaud, constitui um verdadeiro paradigma de análise da regulação jurídica no âmbito da discussão francesa. ${ }^{1}$ Trata-se de uma perspectiva que, diferentemente do que ocorria no âmbito da "sociologia legislativa" de Carbonnier, desvincula a análise sociológica de sua posição ancilar e instrumental relativamente ao processo de reforma da legislação. ${ }^{2}$

O livro intitulado À quoi nous sert le droi?, publicado no final de 2015, consagra, portanto, uma longa e consistente trajetória acadêmica dedicada ao que, nas palavras do próprio autor, poder-se-ia designar como uma "pesquisa de complementaridades" ${ }^{3}$ Trata-se de uma obra na qual Jacques Commaille, retomando e aprofundando análises anteriores, procura mostrar que o direito consiste em um extraordinário revelador das transformações dos modos de regulação social e política. Assim, pretendendo se inscrever na tradição dos fundadores da sociologia, o autor inicia sua análise sublinhando que o direito pode ser enfocado como um paradigma para a compreensão das mutações sociais e políticas contemporâneas. ${ }^{4}$ Neste sentido, visando assumir uma perspectiva resolutamente interdisciplinar, propõe uma redefinição da relação entre a ciência jurídica e as ciências sociais de modo a superar a tendência de desqualificação recíproca que se construiu entre esses âmbitos. ${ }^{\mathbf{5}}$

1 Cf. Arnaud (1998) e Arnaud e Noreau (1998). Acerca da importância da "sociologia política do direito" de Jacques Commaille, ver também: Corten (1998); Delpeuch, Dumoulin e Galembert (2014); García Villegas (2015) e Villas Bôas Filho (2015a).

2 Cf. Commaille (1988 e 2013).

3 A respeito, Commaille (2015, p. 24), referindo-se à sua trajetória, se declara "de plus en plus militant d'une pluri et même d'une interdisciplinarité [...]". Propõe, assim, o que designa de "recherche de complémentarité" (COMMAILLE, 2016a, p. 12).

4 Cf. Commaille (2015 e 2016a).

$5 \quad$ Segundo o autor, “il n'est pas indifférent de se rappeler que ces rapports entre la sociologie, les sciences sociales et le droit sont d'abord des rapports de rejet. En France, la sociologie a disqualifié le droit comme objet de recherche au motif que celui-ci n'était que le 'miroir' et le simple instrument de gestion de rapports sociaux, déterminés par les rapports économiques qui sont ceux de l'économie capitaliste. La science politique a superbement ignoré le droit, masquant par une transposition dans un argumentaire relevant du registre épistémologique ce qui tenait d'abord à un conflit de nature institutionnelle avec les Facultés de droit" (COMMAILLE, 2016a, p. 2). 
A obra é constituída por sete capítulos, divididos em três partes. Na primeira delas, composta dos capítulos I, II e III, Jacques Commaille enfoca a construção social do direito. A segunda, abrangendo os capítulos IV e V, versa sobre as reviravoltas que atingem a regulação jurídica. A terceira parte, que abarca os capítulos VI e VII, dirige-se à análise das mutações atuais da legalidade. Por fim, na conclusão, o autor examina em que medida o direito revela as mutações sociais e as incertezas da ordem política. Para desenvolver essa análise, Commaille mobiliza uma vasta gama de interlocutores dentre os quais se inscrevem, por exemplo, clássicos da sociologia, tais como Émile Durkheim, Karl Marx, Max Weber e Talcott Parsons; grandes filósofos e sociólogos contemporâneos, notadamente Georges Gurvitch, Jürgen Habermas, Louis Althusser, Michel Foucault e Pierre Bourdieu; expressivos teóricos do direito, especialmente Alain Supiot, André-Jean Arnaud, Antoine Garapon, Boaventura de Sousa Santos, François Ost, Jacques Chevallier, Jean Carbonnier, Jean-François Perrin, Jérôme Pélisse, Michel van de Kerchove, Mireille Delmas-Marty, Patricia Ewick, Pierre Lascoumes, Pierre Legendre, Ronald Dworkin e Susan Silbey; autores da antropologia social e jurídica, tais como Claude Lévi-Strauss, Christoph Eberhard, Étienne Le Roy, Louis Assier-Andrieu e Norbert Rouland; e, por fim, historiadores, como Fernand Braudel, François Hartog, Jean Chesnaux e Pierre Rosanvallon. A amplitude e a diversidade de autores mobilizados na obra revelam sua densidade e seu caráter interdisciplinar.

A primeira parte do livro consigna a pretensão de realizar de uma ruptura epistemológica relativamente à representação dominante da legalidade que o autor designa de "juridismo". 6 Segundo ele, tal representação, ao caracterizar o "Direito" como portador de uma "Razão jurídica”, associar-se-ia a uma concepção hierarquizada, piramidal e top down da regulação política e, também, a certas teorias das ciências humanas e sociais que, ao assumirem uma postura radicalmente crítica, inspirada pelo "paradigma da dominação", tenderiam a desenvolver uma perspectiva que entroniza o direito estatal, excluindo, por isso, toda e qualquer possibilidade de resistência. Segundo Jacques Commaille, autores como Michel Foucault e Pierre Bourdieu seriam exemplos expressivos dessa perspectiva, pois ambos tenderiam a focalizar a regulação jurídica como um instrumento a serviço da dominação. Assim, ao enfocar o direito como uma espécie de "máscara do poder", Foucault acabaria por reduzi-lo a um mero dispositivo de controle social que participa da "governamentalidade disciplinar".7

6 A respeito, Commaille (2015, p. 410) ressalta que “j' emploie le qualificatif de 'juridiste’ pour désigner des modes de pensée, des visions du monde social, des manières d'être, découlant étroitement de l'appartenance à l'univers juridique”. Note-se, ademais, que a ruptura epistemológica propugnada pelo autor põe em questão a pretensão de monopólio da representação "juridista” de modo a concebê-la apenas como uma das duas faces do que ele designa de "modèle de légalité duale" (COMMAILLE, 2015, p. 65 e ss.).

7 Caberia indagar se essa descrição não seria matizada pela análise que Fonseca (2012) faz das "imagens" do direito na obra de Foucault. 
Por sua vez, no pensamento de Bourdieu, o direito, concebido como um instrumento eficaz de garantia da reprodução social, serviria ao propósito de perpetuação da dominação e de consagração do status quo.

Contudo, conforme sublinha Jacques Commaille, no âmbito da história do "pensamento jurídico" (pensée juridique) e do "pensamento sobre o direito" (pensée sur le droit), haveria uma outra representação da regulação jurídica que a conectaria à sociedade. Essa representação se expressaria claramente em perspectivas como as de Georges Gurvitch, que sustentava a existência de um direito "imerso" na tessitura social, e Alan Hunt, com sua visão de um direito "constitutivo" da sociedade. ${ }^{8}$ Assim, fazendo alusão a autores como Louis Assier-Andrieu, Pierre Lascoumes e Hartwig Zander, Commaille observa que concepções como as de Gurvitch e Hunt permitiriam vislumbrar a existência de uma juridicidade fundada na consciência do povo paralelamente à legalidade manejada pelos juristas, de modo a substituir a representação clássica de um direito fechado sobre si próprio por outra que o inscreve nas relações sociais. Para o autor, essa representação alternativa abrangeria também autores como Eugen Ehrlich no âmbito da escola do "direito vivo" (Das lebende Recht), Sally Engle Merry, como expressão do movimento Law and Society, e Patricia Ewick e Susan Silbey, como figuras emblemáticas da corrente Legal consciousness. ${ }^{9}$

Essa tentativa de ruptura epistemológica e de distanciamento relativamente à representação convencional do direito, realizada no bojo da primeira parte da obra, se completa com uma abordagem relativa a quem são e o que fazem os atores do direito. Neste sentido, partindo da premissa de que os profissionais do direito são atores sociais, Jacques Commaille enfoca as vicissitudes que incidem e influenciam as práticas de tais atores. Mobilizando os aportes da sociologia das profissões, o autor examina as pressões sociais, políticas, culturais e econômicas que afetam as atividades jurídicas em meio à crise que acomete os profissionais em geral. ${ }^{10}$ Assim, além de analisar aspectos relativos à progressiva fragilização do estatuto social dos profissionais do direito, Commaille aborda também seus reflexos na própria formação jurídica. Nesse contexto, sublinha, sobretudo, a tendência de expansão dos case studies, praticados nas Law Schools americanas, para os mais diversos contextos acadêmicos. Por isso, citando Anne-Sophie Chambon, aponta para o progressivo "déplacement d'un savoir sur ce qu'est le droit vers une connaissance de ce que font les juristes" (COMMAILLE, 2015, p. 152).

8 No que concerne à obra de Gurvitch, ver, especialmente, Commaille (2016b).

9 Poder-se-ia também incluir, no âmbito dessa representação, expressivos teóricos da antropologia jurídica, tais como Étienne Le Roy. Acerca da obra deste autor, ver Villas Bôas Filho (2014 e 2015b).

10 Como ressalta Commaille (2015, p. 150-151), "les pratiques des professionnels du droit et leurs transformations s'inscrivent dans des tendances lourdes auxquelles sont exposées l'ensemble des professions”. 
A segunda parte da obra versa sobre a exigência de um novo quadro analítico para a compreensão do que o direito é capaz de revelar relativamente às mutações da regulação política e social na contemporaneidade. Para desvelar essa questão, Jacques Commaille mobiliza as variáveis "espaço" e "tempo", por ele consideradas determinantes na estruturação da sociedade. ${ }^{11}$ No que concerne à primeira variável, enfatiza que a regulação jurídica se inscreve cada vez mais em um espaço multicêntrico, caracterizado por uma pluralidade crescente de arenas em meio às quais o direito passa a se ancorar em interações múltiplas de agentes inscritos nos níveis local, nacional e supranacional. Logo, aludindo notadamente às análises de Boaventura de Sousa Santos, sustenta a existência de "três espaços jurídicos" que tomariam a forma de uma "legalidade local", uma "legalidade nacional" e uma "legalidade mundial". ${ }^{12}$ Trata-se de um processo que, segundo o autor, expressaria uma "nova economia normativa”, marcada mais por seu caráter horizontal do que vertical. Por conseguinte, mobilizando as considerações de François Ost e Michel van de Kerchove, alude à passagem da "pirâmide” à "rede”. O que fica especialmente evidenciado em tal análise é a progressiva imposição de uma concepção da legalidade que não se enquadra mais em uma visão monista, de modo a demandar uma perspectiva pluralista para o desenvolvimento de uma abordagem adequada da regulação jurídica. Além disso, verifica-se também a paulatina problematização da legitimidade de um processo top down de produção normativa.

Deste modo, Commaille sublinha a passagem de uma concepção do direito como "referência intangível" para outra que o caracteriza como um "recurso" suscetível de ser manejado por atores e por movimentos sociais na consecução dos objetivos por eles almejados. Conforme ressalta o autor, essa tendência relativizaria o papel do Estado, uma vez que reforça a ideia de direitos oponíveis às ordens jurídicas nacionais por cidadãos e grupos que comporiam o que Stanley Hoffman designa de "a new global society". ${ }^{13}$ Observar-se-ia, assim, a emergência de novas formas de mobilização coletiva que, muitas vezes, recorrem à arena judicial visando à preservação ou ao estabelecimento de direitos no plano transnacional. Tudo isso conduz a uma redefinição do papel do Estado e da atividade jurídica. Para analisar essa questão, Commaille aborda, em primeiro lugar, as mudanças profundas ocorridas no âmbito da "jurisdição" do Estado. Em seguida, enfoca as vicissitudes decorrentes da progressiva assunção, pelo direito e pelos tribunais, de uma posição de gestão social. Por fim,

11 A respeito, Commaille (2015, p. 37) ressalta que “je privilégie ici deux 'entrées' pour fonder ma démonstration: celle des territoires (chapitre IV); celle des temporalités (chapitre V), c'est-à-dire ces deux variables déterminantes dans la structuration des sociétés : l'espace et le temps".

12 Commaille (2015, p. 168 e 442) alude, especialmente, à progressiva imposição de uma "légalité mondiale”. Cumpre notar que, a esse respeito, também é feita a menção às perspectivas de autores como Gunther Teubner, Saskia Sassen e Catherine Colliot-Thélène. Sobre essa questão, ver também Chevallier (2008 e 2011). 
focaliza a atividade jurídica em um cenário marcado pelo movimento progressivo de racionalização gerencial do setor público que conduziria a uma espécie de "new public management”. Para empreender tais análises, são mobilizados, especialmente, autores como Bruno Jobert, Jacques Chevallier, Patrice Duran, Pierre Lascoumes, Patrick Le Galès, Jacques Caillosse, Malcolm F. Feeley, Edward Rubin e Ran Hirschl.

A segunda variável mobilizada na análise que Jacques Commaille empreende acerca da capacidade do direito em desvelar as mutações contemporâneas da regulação política e social é o tempo. ${ }^{14}$ Para tanto, partindo da premissa de que tempo e direito são construções sociais, assevera que as alterações no "tempo do direito" ("temps du droit") tornar-se-iam reveladoras das mudanças de estatuto no seio das sociedades. Deste modo, sustentando que as representações do tempo refletiriam as do direito, Commaille associa a primeira "face" do que denomina de "modelo de legalidade dual" (ou seja, aquela designada de "juridista" que define o "Direito" como "Razão") a uma concepção da temporalidade caracterizada pelo que Fernand Braudel qualificava como "la longue durée". ${ }^{15}$ Segundo ele, a essa representação clássica da temporalidade jurídica revelaria uma visão linear na qual o posicionamento no presente se enraizaria no passado para se projetar no futuro. Trata-se, assim, de uma representação que remete para o princípio da permanência. ${ }^{16}$

Ora, nesse contexto, as ciências sociais, justamente porque enfatizam a mudança, entrariam em tensão com essa visão “juridista” que remete à permanência. ${ }^{17}$ Por conseguinte, Commaille, a partir da mobilização de autores como François Hartog, François Ost, Hartmunt Rosa, Zygmunt Bauman e Jean-François Lyotard, aponta os reptos experimentados pela representação "juridista” da temporalidade em virtude das transformações econômicas,

14 A respeito, Commaille (2015, p. 240) ressalta que "le temps que je choisis comme 'entrée' n'est pas un temps conçu de façon abstraite et universelle. Il est ici un temps construit socialement, relatif en fonction des contextes historiques et en fonction des contextes culturels. L'objectif est de comprendre comment le droit est inscrit temporellement dans la vie sociale, culturelle et politique des sociétés et comment ceux qui l'activent participent à cette inscription”. Sobre a questão do tempo como uma construção social, ver, especialmente, Bourdieu (2012 e 1993).

15 A respeito, ver, especialmente, Braudel (1958), Kula (1999) e Perrot (1999).

16 Segundo Commaille (2015), haveria uma espécie de conjugação entre a naturalidade atribuída ao tempo e a que é conferida ao direito.

17 Conforme Commaille (2015, p. 255), “ce choc des temporalités provoque effectivement des effets de grande ampleur sur les représentations des acteurs de la sphère juridique. La pression croissante des temporalités sociales sur les temporalités juridiques est propre à nourrir ce pessimisme qui apparaît comme une grande constante dans la rhétorique juridique et qui s'exprime, comme nous l'avons déjà vu, en termes de 'déclin du droit' ou encore de 'généralisation de l'insécurité juridique' provoquée par le fait de 'privilégier les intérêts du présent””. 
sociais e culturais e também diante das novas formas de regulação política que, ao engendrarem uma aceleração do tempo, desestabilizam essa representação tradicional. O tratamento dessa questão se completa com a análise das "temporalidades extrajurídicas" a partir da qual o autor procura realizar uma confrontação da atividade jurídica com as temporalidades políticas, sociais e culturais. Procura, portanto, demonstrar que, tal como sustenta Peter Fitzpatrick, o direito está "saturado de temporalidades" (COMMAILLE, 2015, p. 259).

A terceira parte da obra se dirige à análise das "mutações contemporâneas da legalidade”. Para tanto, enfoca, inicialmente, a "economia das relações entre a atividade jurídica e a política”, uma vez que se parte da premissa de que as formas de expressão da atividade jurídica inscrever-se-iam em um quadro geral que se exprime na ordenação política das sociedades. Assim, o destino da regulação jurídica seria dependente das novas formas de organização política, especialmente no que tange à globalização. ${ }^{18}$ Por esse motivo, abordar as transformações do direito permitiria o desvelamento das mudanças experimentadas pela ordem política. É, aliás, por esse motivo que considera que a crise da “democracia representativa” e as tentativas de substituí-la por uma "democracia participativa” seriam consubstanciais à contestação da legitimidade da lei oriunda de um processo top down e de uma problematização da "primeira face do modelo de legalidade dual: aquela do 'Direito' como 'Razão" (COMMAILLE, 2015, p. 297). Trata-se da tendência, destacada pelo autor ao longo do livro, de problematização do monopólio de uma representação do "direito como referência" ("droit comme référence") e de reivindicação de um "direito como recurso" ("droit comme ressource") o que, em sua perspectiva, sugeriria uma concepção da regulação jurídica menos fundada sobre a ideia de unidade e de monismo que sobre a de pluralismo. ${ }^{19}$

Deste modo, sublinhando que as incertezas relativas ao porvir da regulação jurídica seriam indissociáveis das que perpassam as da organização política, Commaille reafirma sua tese de que o direito não seria apenas um instrumento de regulação social. Conforme procura ressaltar, para além dessa dimensão regulatória, o direito também desvelaria, de modo excepcional, as finalidades sociais e políticas que o atravessam e, por esse motivo, as formas de regulação que se organizam nessas duas esferas, tal como as tendências de reconfiguração que lhes são ínsitas. ${ }^{20}$ Assim, em termos conclusivos, o autor questiona se o "paradigma

18 A respeito, ver, especialmente, as clássicas análises de Arnaud (1997, 2003 e 2004).

19 Conforme observa Commaille (2015, p. 297), trata-se da "remise en question du monopole d'une représentation du droit comme référence et la revendication d'un droit comme ressource suggèrent une conception de la légalité moins fondée sur l'idée d'unicité, de monisme, que sur celle de pluralisme”. A respeito, no âmbito da discussão francesa, ver, especialmente, Delmas-Marty (2006).

20 Segundo Commaille (2015, p. 381), "le droit est indissociable des sociétés dans lesquelles il ouvre. Le droit n'a pas seulement vocation à réguler ces sociétés dans leurs multiples facettes. Dans ce qu'il énonce, 
da dominação" - representado por importantes autores como Bourdieu e Foucault - remanesceria adequado para a apreensão e explicação das expressivas e complexas transformações assumidas pelos "regimes de regulação social e política" ou se não conviria repensá-lo à luz das tensões decorrentes do "modelo de legalidade dual" apresentado na primeira parte da obra.

Evidentemente que isso não implica desconsiderar os processos de dominação em curso na sociedade contemporânea. Contudo, caberia apontar suas metamorfoses, especialmente no que concerne à sua maior difusão e descentramento que tenderiam a torná-la "policêntrica". ${ }^{21}$ Em meio a isso, o autor procura focalizar as formas de resistência que se delineariam na atualidade. É nesse sentido que, em um artigo publicado logo após a edição da obra, Commaille, com o intuito de sublinhar as estratégias contra-hegemônicas que mobilizam o direito, alude à obra de Michel de Certeau para tratar das "táticas" mobilizadas pelos "mais fracos" para neutralizar ou mitigar as "estratégias" dos "poderosos". ${ }^{22}$ Essa questão remete, segundo o autor, para a necessidade de um "novo modelo de legalidade" que seja capaz de conjugar as complementaridades das duas "faces" constitutivas do "modelo de legalidade dual" para o propósito de implementação de uma sociedade verdadeiramente democrática.

\section{REFERÊNCIAS}

ARNAUD, André-Jean. De la régulation par le droit à l'heure de la globalisation. Quelques observations critiques. Droit et société, v. 35, p. 11-35, 1997.

dans ce qu'on en fait, dans les façons dont il est investi, d'abord par ceux qui ont pour fonction d'en avoir la maîtrise, il nous dévoile aussi, de façon exceptionnelle, ce qu'il porte de finalités sociales et politiques, ce que sont, plus généralement, les modes de régulation sociale et politique des sociétés et ce que sont leurs reconfigurations".

21 Sobre esse ponto, Commaille (2015, p. 400) enfatiza que "l'enjeu est désormais de saisir les causes, les manifestations, les devenirs possibles d'une régulation polycentrique de par la multiplicité de ses polarités et de ses ancrages géographiques et culturels".

22 A respeito, Commaille (2016a, p. 8) afirma que “Michel de Certeau (1980) parle de ces 'tactiques' des 'faibles' susceptibles de neutraliser ou de détourner les 'stratégies' des 'puissants'”. Poder-se-ia aqui pensar no direito como um instrumento para promoção do que Jan Pato ka designava de "la solidarité des ébranlés". 
Le droit trahi par la sociologie. Une pratique de l'histoire. Paris: LGDJ, 1998.

Gouvernants sans frontières. Entre mondialisation et post-mondialisation. v. 2 de la Critique de la raison juridique. Paris: LGDJ, 2003.

. Entre modernité et mondialisation. Leçons d'histoire de la philosophie du droit et de l'État. 2. ed. Paris: LGDJ, 2004.

; NOREAU, Pierre. The sociology of law in France: trends and paradigms. Journal of Law and Society, v. 25, n. 2, p. 257-283, 1998.

BOURDIEU, Pierre. Esprits d'État [Genèse et structure du champ bureaucratique]. Actes de la recherche en sciences sociales, v. 96-97, p. 49-62, mar. 1993.

Sur l'État. Cours au Collège de France 1989-1992. Paris: Éditions Seuil, 2012.

BRAUDEL, Fernand. Historie et sciences sociales: la longue durée. Annales. Économies, Sociétés, Civilisations, n. 4, p. 725-753, 1958.

CHEVALLIER, Jacques. L'État post-moderne. 3. ed. Paris: LGDJ, 2008. L'État. 2. ed. Paris: Dalloz, 2011.

COMMAILLE, Jacques. À quoi nous sert le droit? Paris: Gallimard, 2015.

. À quoi nous sert le droit pour comprendre sociologiquement les incertitudes des sociétés contemporaines? SociologieS [En ligne], Dossiers, Sociétés en mouvement, p. 1-12, 2016a. Disponível em: <http: / / sociologies.revues.org/5278>. Acesso em: 7 mar. 2016.

. Les enjeux politiques d'un régime de connaissance sur le droit. La sociologie du droit de Georges Gurvitch. Droit et société, n. 94, p. 547-563, 2016b.

. The Law and Science: dialectics between the prince and the maidservant. Law and Policy, v. 10, n. $2 \& 3$, p. 253-265, 1988.

. Uma sociologia política do direito. Revista da Faculdade de Direito da USP, v. 108, p. 929-933, 2013.

CORTEN, Olivier. Éléments de définition pour une sociologie politique du droit. Droit et Société, n. 39, p. 347-370, 1998. 
DELMAS-MARTY, Mireille. Les forces imaginantes du droit (II). Le pluralisme ordonné. Paris: Seuil, 2006.

DELPEUCH, Thierry; DUMOULIN, Laurence; GALEMBERT, Claire de. Sociologie du droit et de la justice. Paris: Armand Colin, 2014.

FONSECA, Márcio Alves da. Michel Foucault e o direito. São Paulo: Saraiva, 2012.

GARCÍA VILLEGAS, Mauricio. Les pouvoirs du droit. Analyse comparée d'études sociopolitiques du droit. Paris: LGDJ, 2015.

KULA, Witold. Histoire et économie: la longue durée. In: REVEL, Jacques. Fernand Braudel et l’histoire. Paris: Hachette Littératures, 1999. p. 83-106.

PERROT, Jean-Claude. Le présent et la durée dans l'œuvre de Braudel. In: REVEL, Jacques. Fernand Braudel et l'histoire. Paris: Hachette Littératures, 1999. p. 165-185.

VILLAS BÔAS FILHO, Orlando. Juridicidade: uma abordagem crítica à monolatria jurídica enquanto obstáculo epistemológico. Revista da Faculdade de Direito da USP, v. 109, p. 281-325, jan.-dez. 2014.

. A juridicização e a judiciarização enfocadas a partir da "sociologia política do direito" de Jacques Commaille. Revista Brasileira de Sociologia do Direito, ABraSD, v. 2, n. 2, p. 56-75, jul.-dez. 2015 a.

A regulação jurídica para além de sua forma ocidental de expressão: uma abordagem a partir de Étienne le Roy. Revista Direito \& Práxis, v. 6, n. 12, p. 159-195, 2015b.

Orlando Villas Bôas Filho Professor da Faculdade de Direito da Universidade de São Paulo e da Faculdade de Direito da Universidade PRESBiteriana MACKEnZIE. ovbfausp.br 